\title{
Current methods of diagnosis and treatment of scaphoid fractures
}

\author{
Steven J Rhemrev ${ }^{1 *}$, Daan Ootes ${ }^{1}$, Frank JP Beeres ${ }^{2}$, Sven AG Meylaerts ${ }^{1}$, Inger B Schipper ${ }^{2}$
}

\begin{abstract}
Fractures of the scaphoid bone mainly occur in young adults and constitute 2-7\% of all fractures. The specific blood supply in combination with the demanding functional requirements can easily lead to disturbed fracture healing. Displaced scaphoid fractures are seen on radiographs. The diagnostic strategy of suspected scaphoid fractures, however, is surrounded by controversy. Bone scintigraphy, magnetic resonance imaging and computed tomography have their shortcomings. Early treatment leads to a better outcome. Scaphoid fractures can be treated conservatively and operatively. Proximal scaphoid fractures and displaced scaphoid fractures have a worse outcome and might be better off with an open or closed reduction and internal fixation. The incidence of scaphoid nonunions has been reported to be between 5 and 15\%. Non-unions are mostly treated operatively by restoring the anatomy to avoid degenerative wrist arthritis.
\end{abstract}

\section{Introduction}

The carpal scaphoid bone is known to play a key role in the function of the wrist. Therefore, pathologic abnormalities of the scaphoid may have serious consequences. Scaphoid fractures account for $2-7 \%$ of all fractures and predominantly occur in young, active males. Of all carpal fractures, $82-89 \%$ concern scaphoid fractures. The incidence in Western countries is approximately five fractures in every 10,000 inhabitants [1-3]. However, because of the diagnostic challenge that scaphoid fractures often present, the exact incidence is unknown.

Given the above, the indistinct method of treatment and the tremendous research efforts over the last decade resulting in up to 3,200 PubMed hits, the scaphoid remains one of the most interesting carpal bones for researchers.

\section{Anatomy}

The scaphoid fracture was first described in 1905 by Destot, a French surgeon, anatomist and radiologist [4]. The word scaphoid is derived from the Greek word for boat (skaphos). Because of its unique anatomy it can articulate with all five surrounding bones (distal radius,

\footnotetext{
* Correspondence: s.rhemrev@mchaaglanden.nl

'Department of Trauma Surgery, Medical Centre Haaglanden, The Hague, The Netherlands

Full list of author information is available at the end of the article
}

os capitatum, os lunatum, os trapezium and os trapezoideum).

Eighty percent of the scaphoid bone consists of cartilage, leaving limited space for entrance of the supplying arteries. The main blood supply is through retrograde branches of the radial artery. The dorsal branch of the radial artery provides $75 \%$ of the blood supply through the foramina. The palmar branch reaches the scaphoid via the distal tubercle. Contrary to the proximal pole, the distal pole and the tubercle have an independent vascularisation. The proximal pole depends on blood supply from the distal pole through the scaphoid bone. In case of a proximal scaphoid fracture, the blood supply through the scaphoid bone is interrupted, making the healing process of the proximal pole particularly more difficult [5].

\section{Clinical presentation}

The typical trauma mechanism is a fall on the outstretched hand with the wrist in radial deviation inducing impact of the palm. This trauma mechanism also puts the dorsal radius and the scaphoid-lunatum (SL) ligament at risk. The above-described mechanism causes the scaphoid bone to impact against the distal radius concavity, causing a fracture most likely to occur in the middle of the scaphoid. There is an increased chance of a proximal pole fracture when falls occur on the wrist in abduction [6].

\section{SpringerOpen ${ }^{\odot}$}

(c) 2011 Rhemrev et al; licensee Springer. This is an Open Access article distributed under the terms of the Creative Commons Attribution License (http://creativecommons.org/licenses/by/2.0), which permits unrestricted use, distribution, and reproduction in any medium, provided the original work is properly cited. 
Interestingly, the same trauma mechanism causes supracondylar humeral fractures in children and distal radius or carpal fractures in the elderly [7].

There are no reliable clinical tests to confirm or rule out the diagnosis of a scaphoid fracture. An observable swelling of the anatomic snuffbox (Figure 1) increases the chance of a scaphoid facture. Pain when applying pressure on the anatomic snuffbox or the scaphoid tubercle, or when applying axial pressure on the first metacarpal bone all have a sensitivity of $100 \%$. However, their specificity is $9 \%, 30 \%$ and $48 \%$, respectively [8]. Other studies found a higher specificity for a tender tubercle (57\%). An over 50\% diminished grip strength compared to the contralateral side increases the positive predictive value for a scaphoid fracture $[9,10]$.

\section{Imaging of the scaphoid}

There are several different diagnostic modalities to detect a scaphoid fracture. These include conventional radiographs, computed tomography (CT scans), magnetic resonance examination, bone scintigraphy and sonograms. Each procedure has its specific advantages and disadvantages (Table 1).

\section{Conventional radiographs}

Scaphoid fractures are often missed with the use of conventional radiographs alone. Initial radiographs (Figure 2) detect at most $70 \%$ of all scaphoid fractures [11]. There is still no consensus regarding the different types of conventional radiographs. Anterior-posterior and lateral radiographs should be standard, and at least two additional views are advocated for a suspected scaphoid fracture [12].

Even on the repeated radiographic exam after 10-14 days propagated by many clinicians in case of an occult fracture, a scaphoid fracture is often missed, since the additional sensitivity is low, although in case of sclerosis it could confirm the suspected diagnosis [13-15].

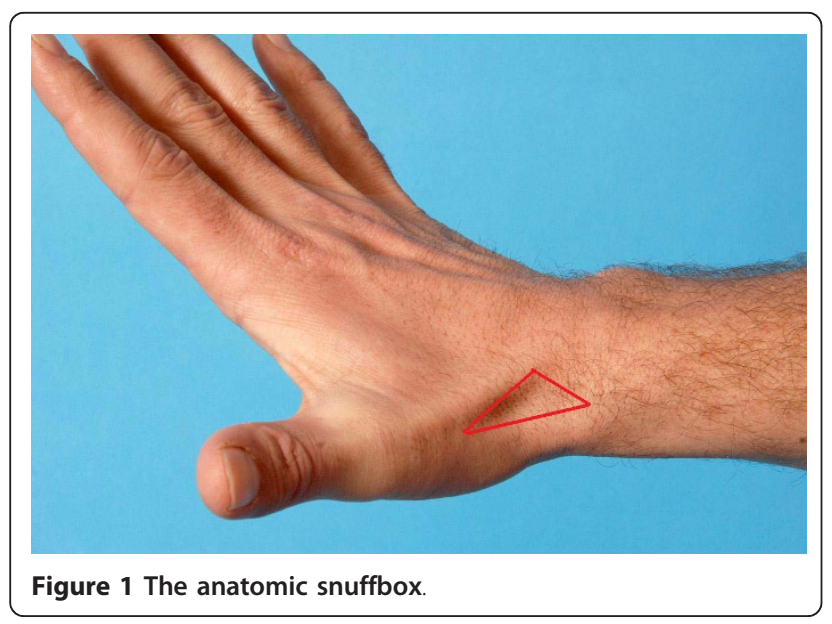

Table 1 Sensitivity and specificity for bone scans, MR examination and CT scans

\begin{tabular}{lll}
\hline & Sensitivity (\%) & Specificity (\%) \\
\hline Bone scan [19] & $100(83-100)$ & $90(81-96)$ \\
MR examination [19] & $80(56-94)$ & $100(96-100)$ \\
CT [48] & $93(83-98)$ & $99(96-100)$ \\
\hline
\end{tabular}

\section{Computed tomography (CT)}

The costs and radiation exposure for a computed tomography (Figure 3) scan are comparatively low. CT is readily available in both hospitals and emergency departments, which enables CT confirmation of a suspected scaphoid fracture. CT imaging also allows adequate judgement of cortical involvement and is therefore often used in the decision-making process concerning whether or not to operate on scaphoid fractures.

Unfortunately, the sensitivity of CT is lower in comparison to bone scintigraphy [16]. A solid statistical statement about the CT as a diagnostic tool for scaphoid fractures is difficult to make because of insufficient inclusion of patients in research to date. Despite the high resolution and multiplanar reconstructions, the difficulty of the interpretation of a CT scan lies in the distinction between channels in the trabecular bone pattern and fractures. This restricts the specificity of the CT scan [16-18].

\section{Bone scintigraphy}

Using a bone scan (Figure 4), scaphoid fractures can be ruled out with a high level of confidence. For this reason it is recommended as a second diagnostic modality of choice after conventional radiographs. The sensitivity is close to $100 \%$, whereas the specificity depends on the modality that is defined as the gold standard for comparison. Bone scintigraphy results in up to $25 \%$ falsepositive outcome measures [15]. The procedure is reliable and relatively fast, but patients have to pay an extra visit to the hospital, and it requires intravenous radioactive isotopes. In addition, bone scintigraphy is expensive [19-21].

\section{Magnetic resonance examination}

Magnetic resonance (MR) examination is often recommended as a diagnostic modality for occult scaphoid fractures (Figure 5) [22,23,13]. Late MR examination (after 19 days) shows better results in comparison to bone scintigraphy in terms of sensitivity and specificity [20]. However, the early MR imaging within 1 day after trauma has a limited sensitivity of $80 \%$ [19]. The interpretation of a MR examination depends strongly on the experience of the clinician. When adequately performed, MR examination enables simultaneous diagnosis of soft 


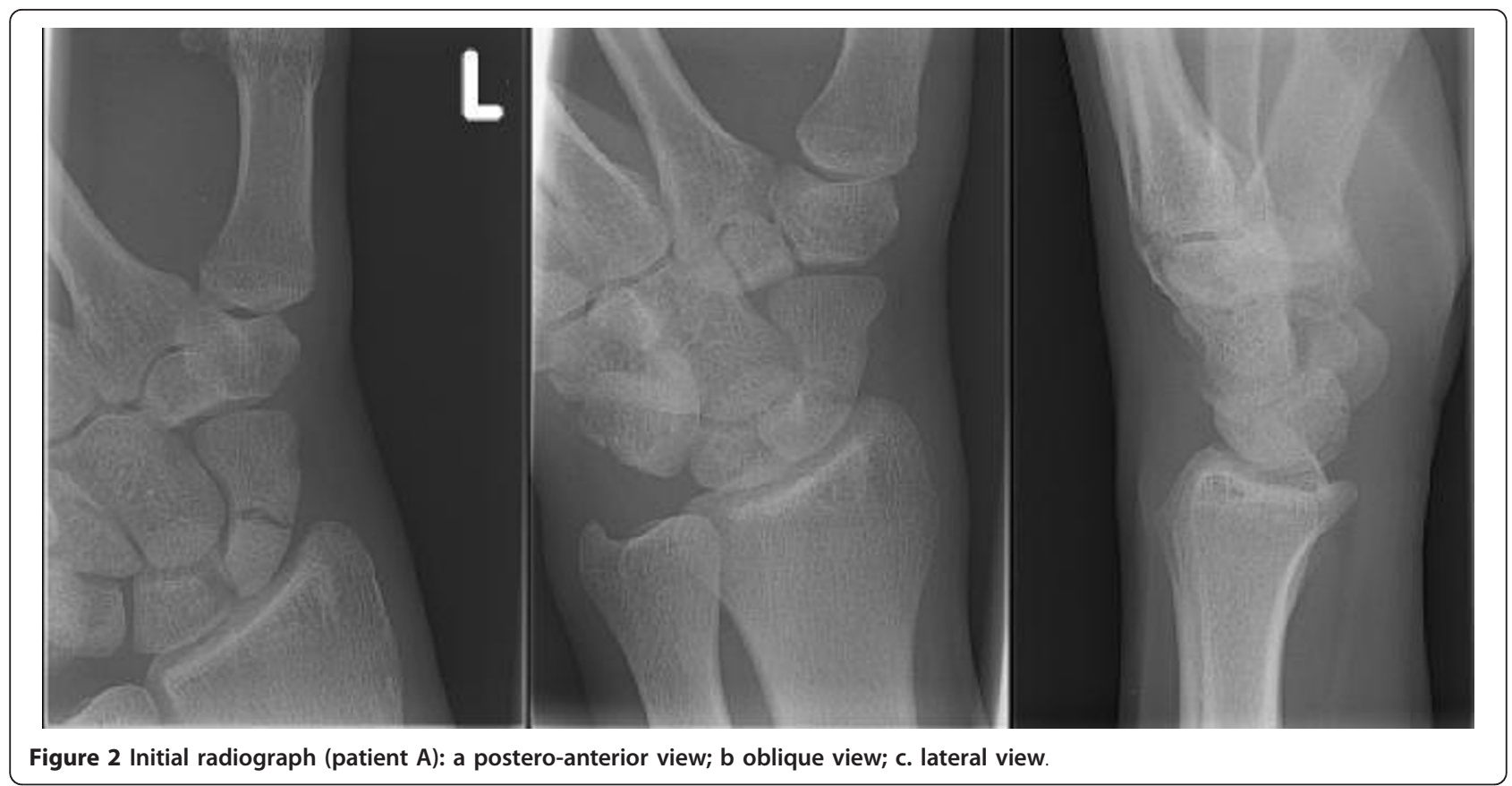

tissue and ligament injuries. Considerable experience is needed for the distinction between swelling and oedema, micro-fractures or incomplete fractures, or complete but nondislocated fractures. The MR examination also has infrastructural restrictions. Not every hospital has an MR scan, and if available there are often many structural and organizational problems to overcome.

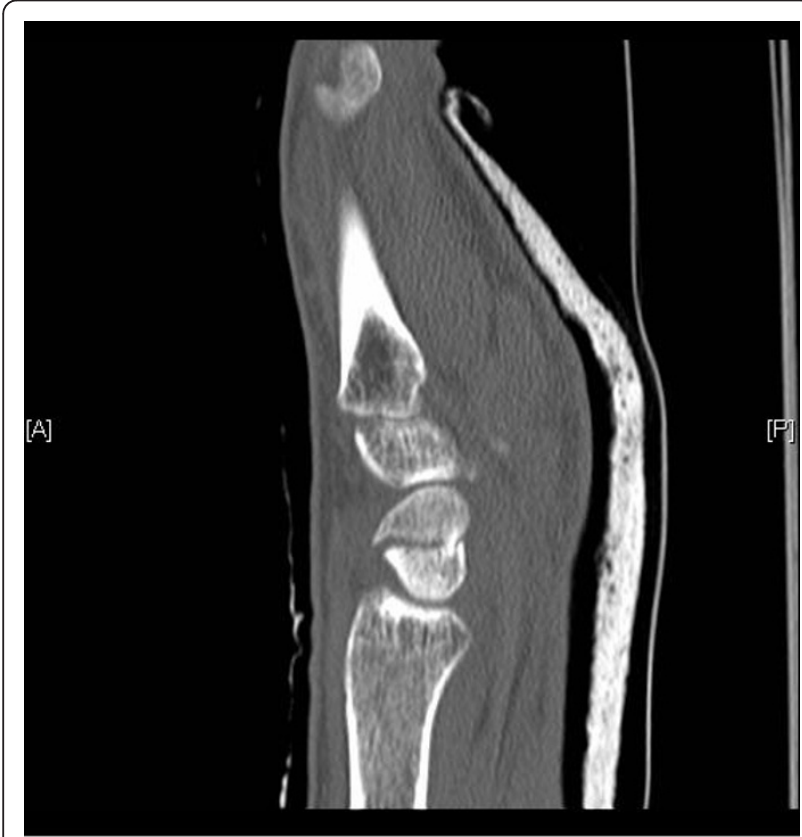

Figure 3 CT scan (patient B) sagittal view of a fractured scaphoid.

\section{Sonogram}

The routine use of ultrasound is not indicated to diagnose a scaphoid fracture. Low-frequency ultrasound has not proven to be of any advantage, whereas high-frequency ultrasound can be helpful in the diagnosis of a scaphoid fracture. The interpretation of ultrasound is again dependant on the level of experience of the

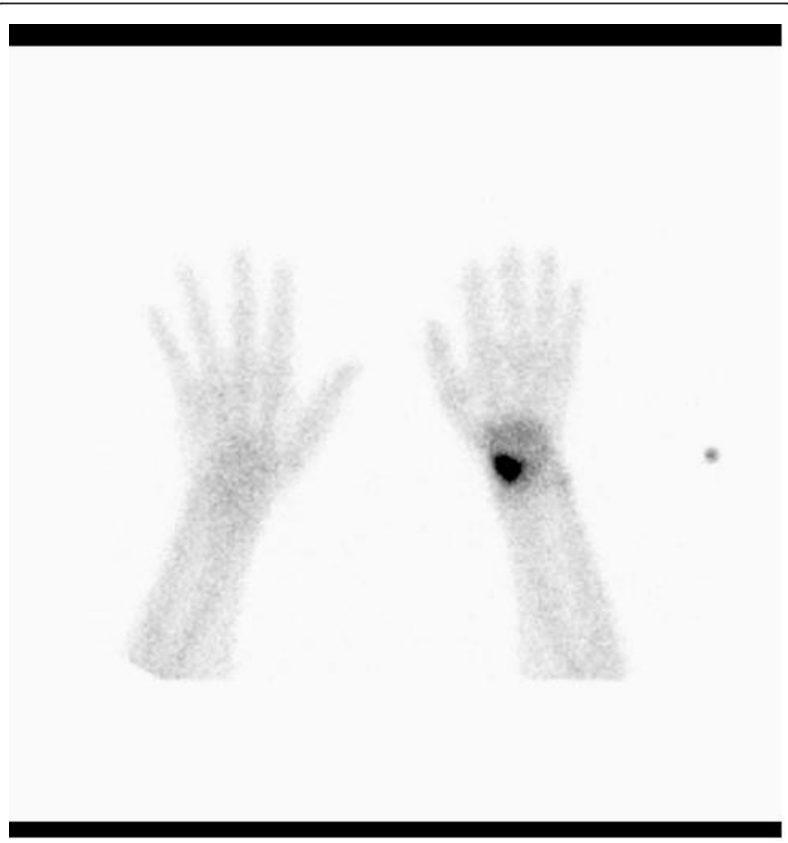

Figure 4 Bone scintigraphy (patient $C$ ) of the hands the patient with a scaphoid fracture on the right side. 


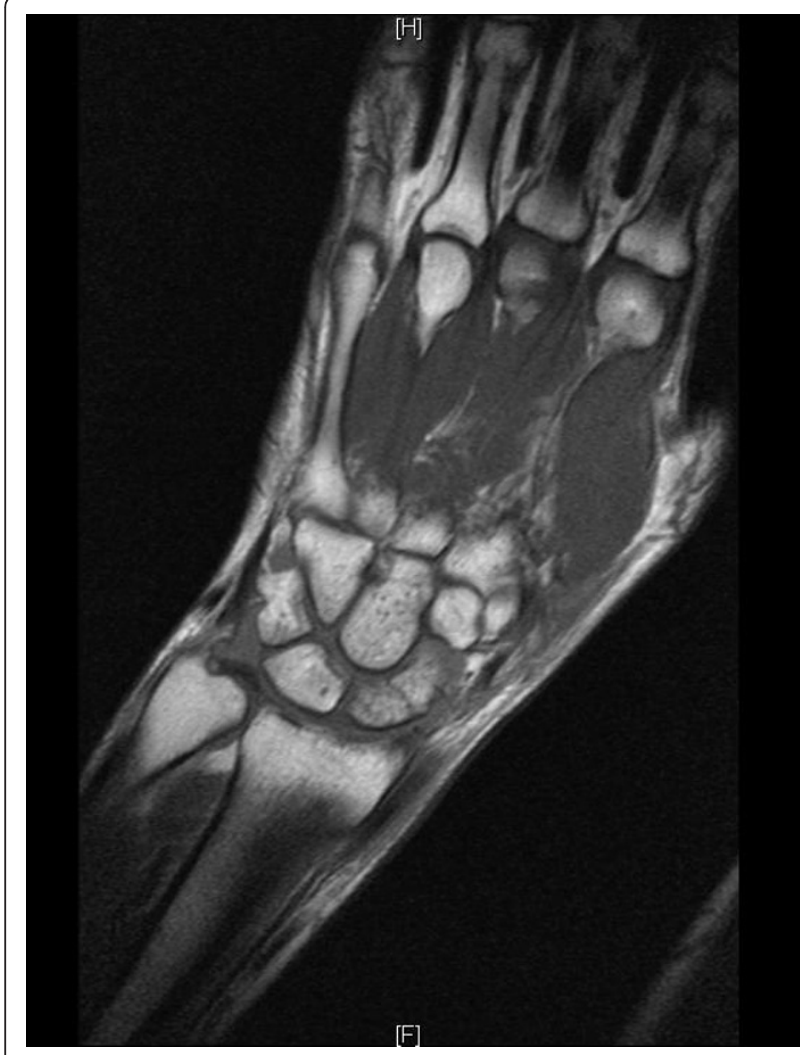

Figure 5 Magnetic resonance imaging (patient D) of a waist fracture of the scaphoid

clinician. The use of ultrasound in the diagnostic process of an occult scaphoid fracture is still subject to research and therefore not yet established as a useful standard diagnostic modality [24,25].

In conclusion, a gold standard with a positive predictive value of $100 \%$ for scaphoid fractures does not currently exist. Routine radiographs at baseline are mandatory, and repeated radiographs are not indicated to detect occult scaphoid fractures. Univocal data regarding the advocated diagnostic tool for imaging suspected scaphoid fractures are still limited.

\section{Classification of scaphoid fractures}

Many classifications are used for carpal scaphoid fractures. Three will be discussed here in order of their clinical relevance.

\section{Herbert classification}

The Herbert classification [26] is based on the stability of the fracture. Unstable fractures are fractures with a dislocation of more than $1 \mathrm{~mm}$ or an angulation of more than $15^{\circ}$ between the fragments. Additional fractures, trans-scaphoid-perilunate dislocations, multifragment fractures and proximal pole fractures are also classified as unstable.

\section{MAYO classification}

The MAYO classification [27] (Figure 6) divides scaphoid fractures into proximal (Figure 7) (10\%), middle (70\%) and distal (20\%) fractures. Within the distal third, distinction is made between the distal articular surface and the distal tubercle.

\section{Russe classification}

The anatomic classification according to Russe [28] predicts the tendency of the fracture to heal. The classification distinguishes among horizontal oblique, transverse or vertical oblique fracture lines. The vertical oblique fracture is unstable, whereas the horizontal oblique and the transverse fractures are more stable fractures.

\section{Treatment}

The aim of the treatment is to achieve fracture consolidation and functional recovery whilst avoiding complications such as non- or mal-union. Therapeutic options consist of direct functional treatment, cast immobilisation of the fracture and joints, and operative treatment.

\section{Direct functional treatment}

The literature shows that a scaphoid fracture can be treated functionally. In case of a clinically suspected scaphoid fracture without radiological signs of a fracture, early functional treatment can be started using a bandage or an orthosis. Patients with persistent clinical suspicion of a scaphoid fracture should have repeated radiological evaluation within 7 days after the trauma to evaluate the current treatment strategy and to potentially adjust the treatment strategy as a result based on the radiographic findings.

Inadequate immobilisation of a scaphoid fracture increases the chances for pseudo-arthrosis by $30 \%$ [29-31]. We therefore believe that there is no indication to treat a proven scaphoid fracture functionally without cast immobilisation or operative fixation.

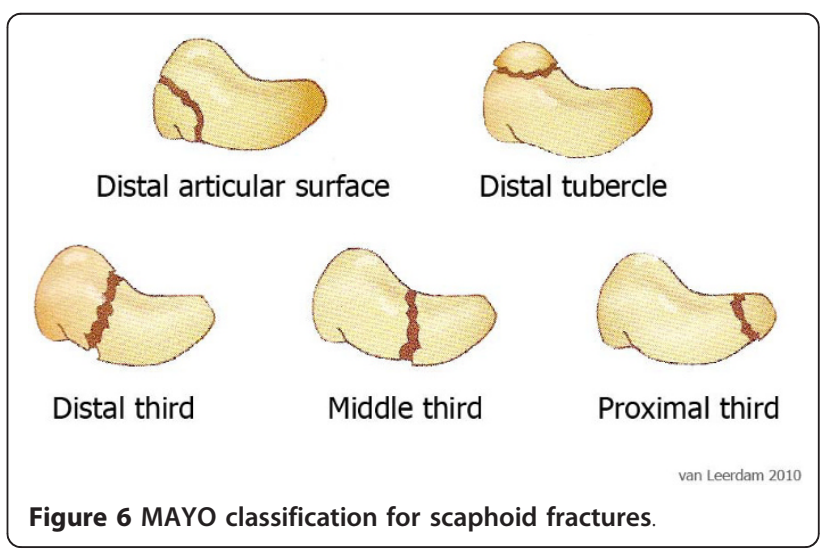




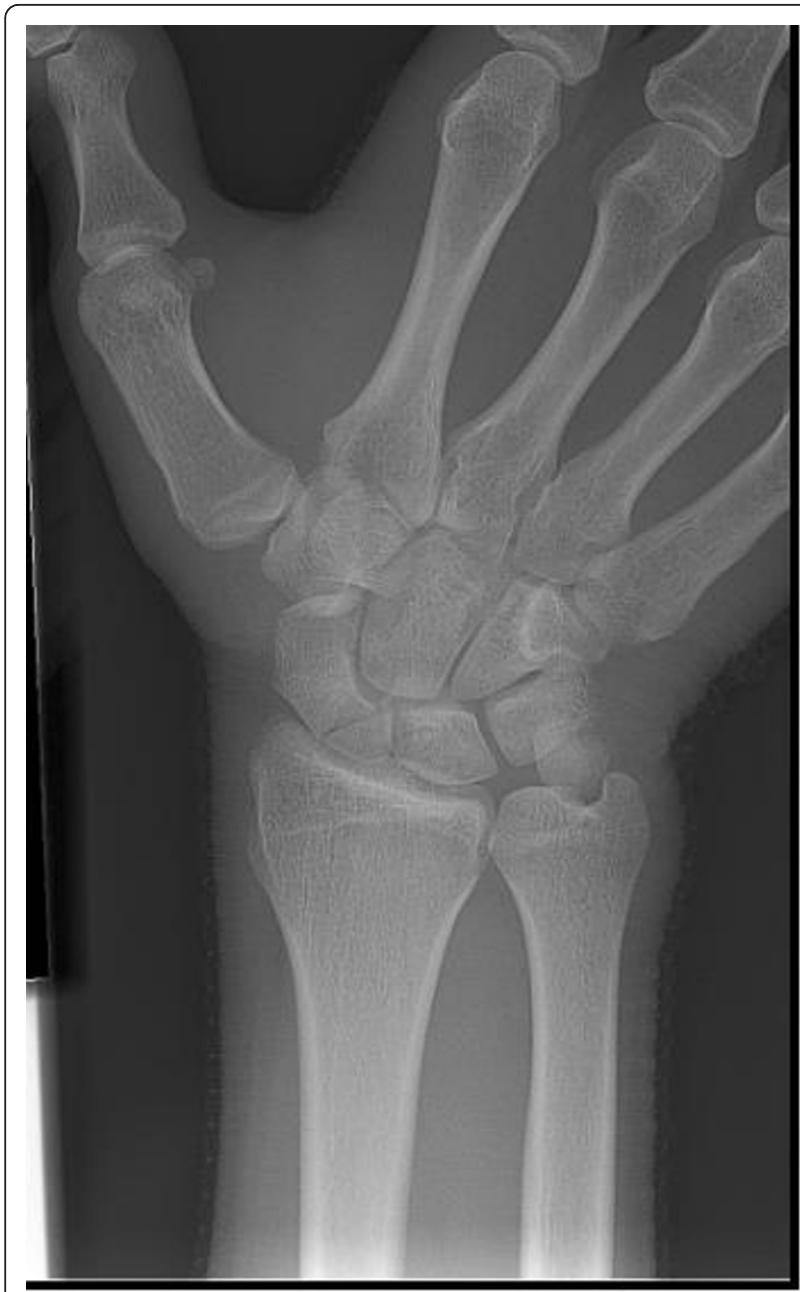

Figure 7 Proximal pole fracture (patient E) on a conventional radiograph.

\section{Cast immobilisation}

In case of an occult or stable scaphoid fracture according to the current Herbert classification, cast immobilisation is still the therapy of choice.

Scaphoid fractures are hard to immobilise, since nearly every motion of the hand, wrist and forearm causes movement of the bone and pressure on the fracture line. Therefore, even an "above the elbow" cast may be applied [32].

There are different types of cast immobilisation for a scaphoid fracture either with or without inclusion of the thumb. There is no study proving a better consolidation with regard to the type of cast that is used; however immobilisation in slight dorsal extension seems to have a positive effect on the grip strength and range of motion of the wrist joint [33-35].

The duration of immobilisation varies, depending on the type of fracture and the outcome on repeated radiological check-ups, which serve as an estimation of fracture consolidation. Generally, a cast treatment of 6 weeks (Figure 8) should be sufficient in most nondisplaced and stable fractures [36]. Cast immobilisation has been proven to be a reliable and successful treatment with low costs and a low complication rate.

\section{Operative treatment}

With improved, minimally invasive surgical techniques, surgical treatment of non-displaced scaphoid fractures has increased. The advantage of operative management with percutaneous screw fixation (Figure 9) in a nondisplaced fracture is the possibility of early functional treatment [37-39].

Operative treatment is indicated in unstable fractures according to the Herbert classification. However, there is no uniformity of opinion on the operative treatment of a non-dislocated fracture of the proximal pole. The scaphoid bone can be approached both from dorsal and volar directions. Distal and middle fractures are best approached from the volar side because of good exposure and conservation of the blood supply. Displaced proximal pole fractures require a dorsal approach because accurate placement of the screw will then be easier to perform. Because of the improved minimally invasive surgical techniques with limited trauma, an increase in surgically treated patients has evolved $[40,38]$. In this manner, a prolonged immobilization period of often 8-12 weeks can be prevented. Wrist stiffness and reduced wrist strength were less frequently observed if a surgical procedure was successful. Moreover, the demand for strategies that allow early productivity of the young patient and the relatively high cost of prolonged immobilization have contributed to the shift towards surgical interventions. There is, however, still insufficient evidence concerning which treatment is preferable for the non-displaced scaphoid fracture [37].

\section{Complications}

Both conservative and operative treatment may cause complications. These include delayed union, osteonecrosis, pseudo-arthrosis and the related instability, arthrosis and collapse of the carpal joint. These complications may result in serious functional restrictions with regard to mobility and grip strength. Additional complications in case of an operation are malalignment, failure to place the screw, re-operation, infections and soft tissue injuries.

In case of a delayed union of the scaphoid fracture, a bone stimulator or magnetic field therapy can be used to achieve bone union [41]. Medicinal treatments are also described. However, evidence-based data are limited, and therefore this treatment is not generally accepted [42].

Pseudo-arthrosis often remains asymptomatic, and may become evident and symptomatic in case of a new trauma or in case of excess strain of the wrist joint. 


\section{Treatment of Scaphoid fractures}

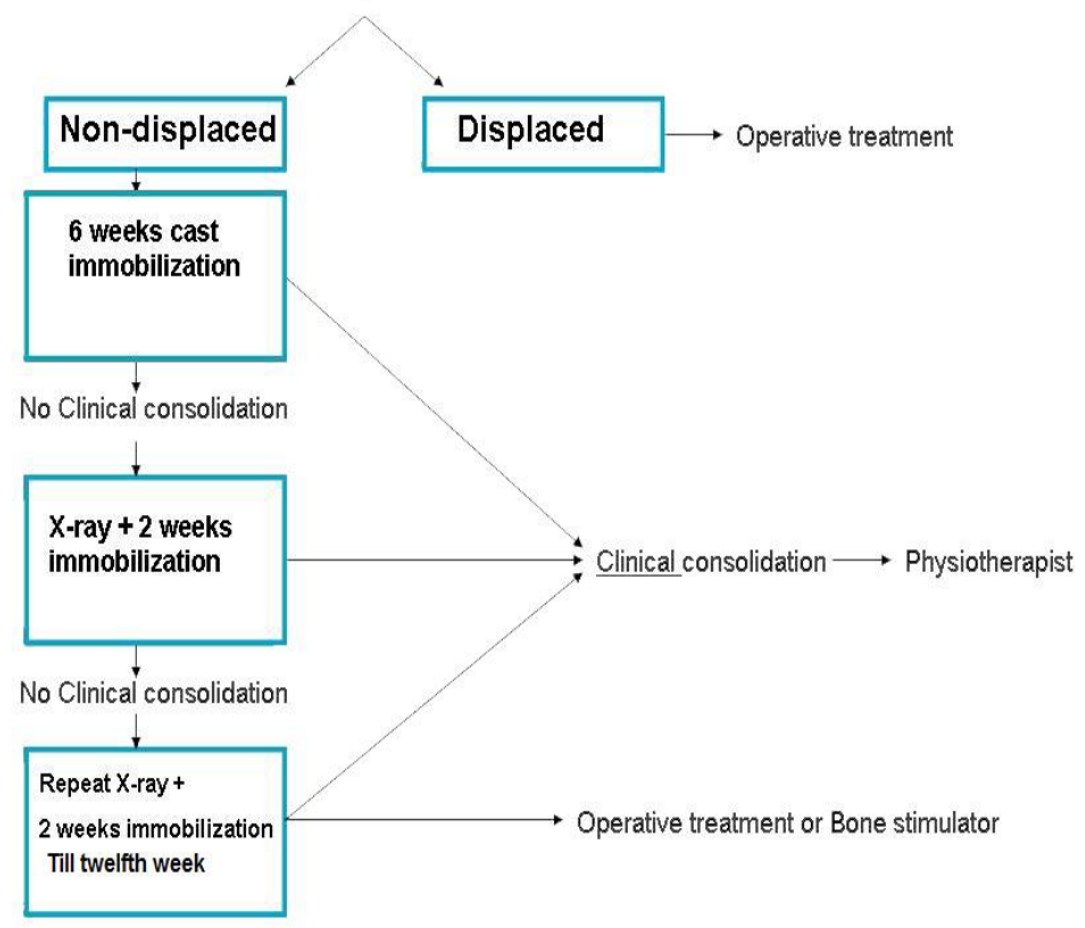

Figure 8 Treatment of scaphoid fractures.

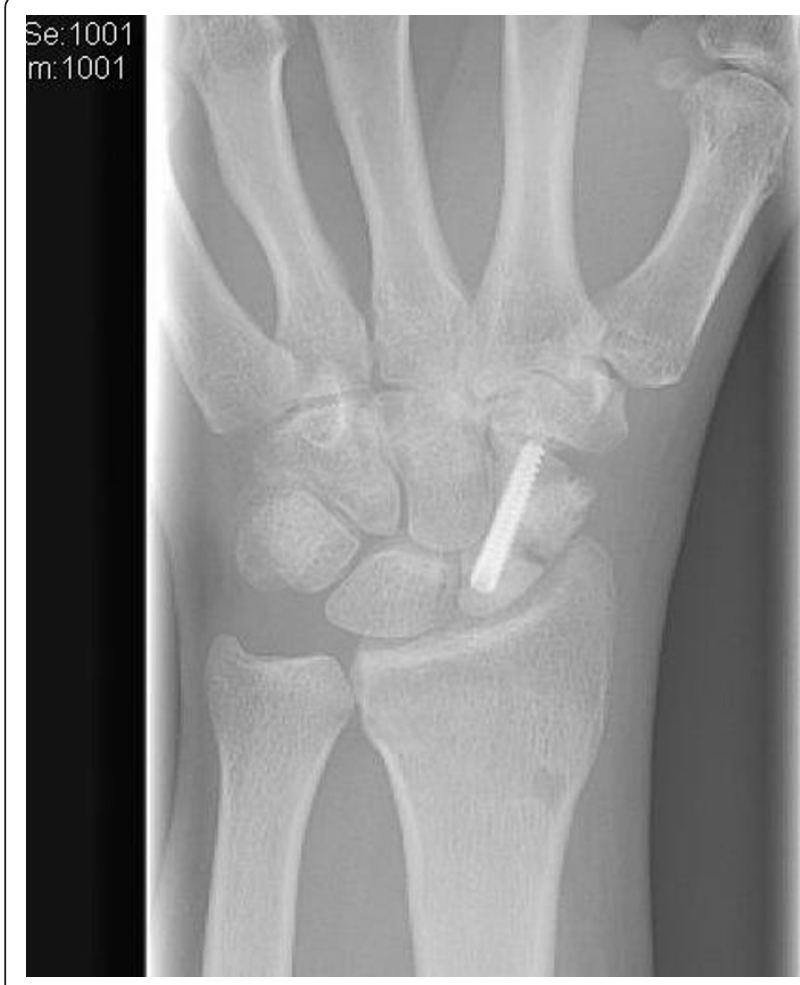

Figure 9 X-ray after percutaneous screw fixation of the scaphoid (patient F).
Pseudo-arthrosis in case of an operative treatment depends on the type of fracture and varies between 5 and $50 \%[43,44]$. A symptomatic pseudo-arthrosis is best treated operatively. Anatomical fracture reduction and intra-articular alignment will prevent an early arthrosis. Several operational techniques have been described. These always include debridement, realignment and implementation of a native vascularised or non-vascularised bone grafting, with or without the use of osteosynthesis $[45,46,28]$. The success rate of this procedure is between 74 and $94 \%$. In case of proximal pseudo-arthrosis, the results are much worse [47]. There are no prospective randomized clinical trials that compare vascularised and non-vascularised bone grafting.

Arthrosis can be a late complication of a scaphoid fracture. A sustainable reduction of pain and functional improvement are often no longer achieved in such cases. The so-called rescue operations in case of arthrosis are styloidectomy, denervation of the carpal joint, and the total or partial removal of the scaphoid with four-quadrant fusion (lunate bone, triquetral bone, capitate bone and hamate bone).

Very few evidence-based data exist regarding the treatment of and diagnostic modalities for scaphoid fractures. 
Scaphoid non-union remains a difficult problem. Early recognition and improvement in treatment will decrease the incidence of this problem and will avoid late complications.

\section{Author details}

'Department of Trauma Surgery, Medical Centre Haaglanden, The Hague, The Netherlands ${ }^{2}$ Department of Trauma Surgery, Leids University Medical Centre, Leiden, The Netherlands

\section{Authors' contributions}

SR: collected the data, put the conclusions together and drafted the manuscript.

DO: helped to find all the articles together, found the highlights, and drafted a part of the manuscript.

FB: particepated in the design of the study helped with the statistics. SM: participated in the design of the study.

IS: conceived of the study and helped with the final manuscript.

\section{Competing interests}

No funds were received in support of this study.

S.J. Rhemrev, M.D.

Steven Rhemrev has been a trauma surgeon since 2001. He attended the University of Amsterdam Medical School in 1985. In 1995 he started his training for General Surgery at the Free University Medical Centre Amsterdam under the supervision of Prof. Dr. Haarman. In the past years he has continued his residency in Trauma Surgery at Medical Centre Alkmaar. He specialised in Traumatology at the VU Medical Centre with Prof. Dr. Patka and Prof. Dr. Haarman (2001-2003). He received a fellowship in Orthopaedic Trauma at Zams, Austria, and at the Liverpool Trauma Centre in Sydney, Australia. From 2003 to the present he has been working at the Medical Centre Haaglanden, which is a level 1 trauma centre in The Hague, The Netherlands, as a surgeon specialised in Trauma Surgery. He is the medical head of the Accident and Emergency Department. Since 2002 he has been doing research mainly on the upper extremities, especially the scaphoid bone.

D. Ootes, M.S.

Daan Ootes is a medical student.

F.J.P. Beeres M.D., PhD.

Frank Beeres is a third year resident at the Medical Centre Haaglanden.

S.A.G. Meylaerts M.D., PhD.

Sven Meylaerts is a trauma surgeon at the Medical Centre Haaglanden and consultant for the Accident and Emergency Department.

I.B. Schipper M.D., PhD.

Prof. Dr. Inger Schipper is a trauma surgeon at the Leids University Medical Centre.

Received: 29 March 2010 Accepted: 4 February 2011

Published: 4 February 2011

\section{References}

1. Brauer RB, Dierking M, Werber KD: Use of the Herbert screw with the freehand method for osteosynthesis of acute scaphoid fractures. Unfallchirurg 1997, 100(10):776-81.

2. Kozin SH: Incidence, mechanism, and natural history of scaphoid fractures. Hand Clin 2001, 17(4):515-24.

3. Schaefer M, Siebert HR: [Fracture of the semilunar bone]. Unfallchirurg 2002, 105(6):540-52.

4. Destot E: La poignet et les accidents du travail: étude radiographique et clinique. Vitot Freres 1905.

5. Gelberman RH, Menon J: The vascularity of the scaphoid bone. J Hand Surg Am 1980, 5(5):508-13.

6. Weber ER, Chao EY: An experimental approach to the mechanism of scaphoid waist fractures. J Hand Surg Am 1978, 3(2):142-8.

7. Schmidt-Neuerburg KP: Tscherne Unfallchirurgie. Ellenbogen, Unterarm, Handi, 120012.

8. Freeland P: Scaphoid tubercle tenderness: a better indicator of scaphoid fractures? Arch Emerg Med 1989, 6(1):46-50.

9. Grover R: Clinical assessment of scaphoid injuries and the detection of fractures. J Hand Surg Br 1996, 21(3):341-3.
10. Parvizi J, Wayman J, Kelly P, Moran CG: Combining the clinical signs improves diagnosis of scaphoid fractures. A prospective study with follow-up. J Hand Surg Br 1998, 23(3):324-7.

11. Bhat M, McCarthy M, Davis TR, Oni JA, Dawson S: MRI and plain radiography in the assessment of displaced fractures of the waist of the carpal scaphoid. J Bone Joint Surg Br 2004, 86(5):705-13.

12. Cheung GC, Lever CJ, Morris AD: X-Ray diagnosis of acute scaphoid fractures. J Hand Surg Br 2006, 31(1):104-9.

13. Coblenz G, Christopoulos G, Fröhner S, Kalb KH, Schmitt R: [Scaphoid fracture and nonunion: current status of radiological diagnostics]. Radiologe 2006, 46(8):664, 666-76.

14. Low G, Raby N: Can follow-up radiography for acute scaphoid fracture still be considered a valid investigation? Clin Radiol 2005, 60(10):1106-10

15. Tiel-van Buul MM, van Beek EJ, Borm JJ, Gubler FM, Broekhuizen AH, van Royen EA: The value of radiographs and bone scintigraphy in suspected scaphoid fracture. A statistical analysis. J Hand Surg Br 1993, 18(3):403-6.

16. Breederveld RS, Tuinebreijer WE: Investigation of computed tomographic scan concurrent criterion validity in doubtful scaphoid fracture of the wrist. J Trauma 2004, 57(4):851-4

17. Memarsadeghi M, Breitenseher MJ, Schaefer-Prokop C, Weber M, Aldrian S, Gäbler C, Prokop M: Occult scaphoid fractures: comparison of multidetector CT and MR imaging-initial experience. Radiology 2006, 240(1):169-76.

18. Ring D, Lozano-Calderón S: Imaging for suspected scaphoid fracture. J Hand Surg Am 2008, 33(6):954-7.

19. Beeres FJ, Rhemrev SJ, den Hollander P, Kingma LM, Meylaerts SA, le Cessie S, Bartlema KA, Hamming JF, Hogervorst M: Early magnetic resonance imaging compared with bone scintigraphy in suspected scaphoid fractures. J Bone Joint Surg Br 2008, 90(9):1205-9.

20. Fowler C, Sullivan B, Williams LA, McCarthy G, Savage R, Palmer A: A comparison of bone scintigraphy and MRI in the early diagnosis of the occult scaphoid waist fracture. Skeletal Radiol 1998, 27(12):683-7.

21. Pillai A, Jain M: Management of clinical fractures of the scaphoid: results of an audit and literature review. Eur J Emerg Med 2005, 12(2):47-51.

22. Breitenseher MJ, Trattnig S, Gäbler C, Happel B, Bankier A, Kukla C, Rand T, Imhof H: MRI in radiologically occult scaphoid fractures. Initial experiences with 1.0 Tesla (whole body-middle field equipment) versus 0.2 Tesla (dedicated low-field equipment. Radiologe 1997, 37(10):812-8.

23. Brydie A, Raby N: Early MRI in the management of clinical scaphoid fracture. Br J Radiol 2003, 76(905):296-300.

24. Fusetti C, Poletti PA, Pradel PH, Garavaglia G, Platon A, Della Santa DR, Bianchi S: Diagnosis of occult scaphoid fracture with high-spatialresolution sonography: a prospective blind study. J Trauma 2005, 59(3):677-81.

25. Herneth AM, Siegmeth A, Bader TR, Ba-Ssalamah A, Lechner G, Metz VM, Grabenwoeger F: Scaphoid fractures: evaluation with high-spatialresolution US initial results. Radiology 2001, 220(1):231-5.

26. Herbert TJ, Fisher WE: Management of the fractured scaphoid using a new bone screw. J Bone Joint Surg Br 1984, 66(1):114-23.

27. Cooney WP: Scaphoid fractures: current treatments and techniques. Instr Course Lect 2003, 52:197-208.

28. Russe O: Fracture of the carpal navicular. Diagnosis, non-operative treatment, and operative treatment. J Bone Joint Surg Am 1960, 42A:759-68.

29. Furunes H, Vandvik PO: [Cast immobilisation for suspected scaphoid fractures]. Tidsskr Nor Laegeforen 2009, 129(3):177-9.

30. Langhoff $\mathrm{O}$, Andersen $\mathrm{J}$ : Consequences of late immobilization of scaphoid fractures. J Hand Surg Br 1988, 13(1):77-9.

31. Sjolin SU, Andersen JC: Clinical fracture of the carpal scaphoidsupportive bandage or plaster cast immobilization? J Hand Surg Br 1988, 13(1):75-6.

32. Kaneshiro SA, Failla JM, Tashman S: Scaphoid fracture displacement with forearm rotation in a short-arm thumb spica cast. J Hand Surg Am 1999, 24(5):984-91.

33. Clay NR, Dias JJ, Costigan PS, Gregg PJ, Barton NJ: Need the thumb be immobilised in scaphoid fractures? A randomised prospective trial. J Bone Joint Surg Br 1991, 73(5):828-32.

34. Gellman H, Caputo RJ, Carter V, Aboulafia A, McKay M: Comparison of short and long thumb-spica casts for non-displaced fractures of the carpal scaphoid. J Bone Joint Surg Am 1989, 71(3):354-7. 
35. Hambidge JE, Desai W, Schranz PJ, Compson JP, Davis TR, Barton NJ: Acute fractures of the scaphoid. Treatment by cast immobilisation with the wrist in flexion or extension? J Bone Joint Surg Br 1999, 81(1):91-2.

36. Rhemrev SJ, van Leerdam RH, Ootes D, Beeres FJ, Meylaerts SA: Nonoperative treatment of non-displaced scaphoid fractures may be preferred. Injury 2009, 40(6):638-41.

37. Bhandari M, Hanson BP: Acute nondisplaced fractures of the scaphoid. J Orthop Trauma 2004, 18(4):253-5.

38. McQueen MM, Gelbke MK, Wakefield A, Will EM, Gaebler C: Percutaneous screw fixation versus conservative treatment for fractures of the waist of the scaphoid: a prospective randomised study. J Bone Joint Surg Br 2008, 90(1):66-71.

39. Vinnars B, Pietreanu M, Bodestedt A, Ekenstam F, Gerdin B: Nonoperative compared with operative treatment of acute scaphoid fractures. A randomized clinical trial. J Bone Joint Surg Am 2008, 90(6):1176-85.

40. Bond CD, Shin AY, McBride MT, Dao KD: Percutaneous screw fixation or cast immobilization for nondisplaced scaphoid fractures. J Bone Joint Surgery Am 2001, 83-A(4):483-8.

41. Mayr E, Rudzki MM, Rudzki M, Borchardt B, Häusser H, Rüter A: Does low intensity, pulsed ultrasound speed healing of scaphoid fractures? Handchir Mikrochir Plast Chir 2000, 32(2):115-22.

42. Novicoff WM, Manaswi A, Hogan MV, Brubaker SM, Mihalko WM, Saleh KJ: Critical analysis of the evidence for current technologies in bone-healing and repair. J Bone Joint Surg Am 2008, 90(Suppl 1):85-91.

43. Bohler J, Ender HG: [Pseudarthrosis of the scaphoid]. Orthopade 1986, 15(2):109-20.

44. Scharf W, Vécsei $V$, Trojan E: [Delayed union and pseudarthrosis of the carpal navicular: diagnosis and treatment (author's transl)]. Unfallchirurgie 1982, 8(1):8-13.

45. Fernandez DL: A technique for anterior wedge-shaped grafts for scaphoid nonunions with carpal instability. J Hand Surg Am 1984 9(5):733-7.

46. Matti H: Über die Behandlung der Navikularefraktur und der Refractura Patellae durch Plombierung mit Spongiosa. Zentralbl Chir 1937, 64:2353-2369.

47. Merrell GA, Wolfe SW, Slade JF: Treatment of scaphoid nonunions: quantitative meta-analysis of the literature. J Hand Surg Am 2002, 27(4):685-91.

48. Yin ZG, Zhang JB, Kan SL, Wang XG: Diagnosing suspected scaphoid fractures: a systematic review and meta-analysis. Clin Orthop Relat Res 2010, 468(3):723-34.

doi:10.1186/1865-1380-4-4

Cite this article as: Rhemrev et al.: Current methods of diagnosis and treatment of scaphoid fractures. International Journal of Emergency Medicine 2011 4:4.

\section{Submit your manuscript to a SpringerOpen ${ }^{\circ}$ journal and benefit from:}

- Convenient online submission

- Rigorous peer review

- Immediate publication on acceptance

- Open access: articles freely available online

- High visibility within the field

- Retaining the copyright to your article

Submit your next manuscript at $\gg$ springeropen.com 